\title{
The effects of high fat diet on the basal activity of the hypothalamus-pituitary-adrenal axis in mice
}

\author{
Hanna E Auvinen', Johannes A Romijn", Nienke R Biermasz , Hanno Pijl', Louis M Havekes ${ }^{1,2}$, \\ Johannes W A Smit ${ }^{1}$, Patrick C N Rensen ${ }^{1}$ and Alberto M Pereira ${ }^{1}$ \\ ${ }^{1}$ Department of Endocrinology and Metabolic Diseases, Leiden University Medical Center, Room C5-R61, Albinusdreef 2, PO Box 9600, 2300 RC Leiden, \\ The Netherlands \\ ${ }^{2}$ TNO-Metabolic Health Research, Gaubius Laboratory, PO Box 2215, 2333 CK Leiden, The Netherlands \\ (Correspondence should be addressed to H E Auvinen; Email: h.e.auvinen@lumc.nl)
}

\begin{abstract}
Alterations in hypothalamus-pituitary-adrenal (HPA) axis activity have been linked to the development of the metabolic syndrome (MetS). Common features of the MetS, like insulin resistance and obesity, are reproducibly induced by high fat diet (HFD) in animal models of diet-induced obesity. These models, hampered by methodological differences, reveal conflicting results with respect to HPA axis activation. This study was aimed to evaluate in detail nonstressed diurnal HPA axis activity in mice during obesity development. Male C57Bl/6J mice were fed high or low fat diet for 12 weeks. HPA axis activity was evaluated by plasma corticosterone concentrations (at 0700,1200 , and $1800 \mathrm{~h}$ ), corticotropinreleasing hormone $(\mathrm{CRH})$, and glucocorticoid receptor (GR) mRNA expression in the hippocampus, amygdala, and hypothalamus, and $11 \beta$-hydroxysteroid dehydrogenase type-1 and -2 (11ß-HSD-1 and -2) expression in adipose
\end{abstract}

tissue and liver. Within 1 week, the HFD induced obesity and decreased corticosterone levels at 1200 and $1800 \mathrm{~h}$, which persisted throughout the experiment. Twelve weeks of HFD decreased $\mathrm{CRH}$ mRNA in the paraventricular nucleus (PVN) and amygdala and GR mRNA in the PVN at 0900 h. At $1800 \mathrm{~h}, \mathrm{CRH}$ mRNA expression increased in the PVN and amygdala, and GR mRNA increased in the CA1 region. 11 $\beta-\mathrm{HSD}-1$ expressions decreased in gonadal, visceral, and subcutaneous adipose tissues at 0900 and $1800 \mathrm{~h}$, whereas hepatic $11 \beta$-HSD-1 expression increased at $1800 \mathrm{~h}$, whereas $11 \beta$-HSD-2 expression was unaffected. The HFD induces complex changes in the diurnal regulation of the different components of the HPA axis. These changes are not unequivocally characterized by increased, but rather by decreased HPA axis activity.

Journal of Endocrinology (2012) 214, 191-197

\section{Introduction}

Glucocorticoids (GCs; cortisol in humans and corticosterone in rodents) are secreted by the adrenals in response to stimulation of the hypothalamus-pituitary-adrenal (HPA) axis by a stressor, and induce behavioral and metabolic adaptations enabling the host to adequately coping with the stressor (fight or flight). Increased activity of the HPA axis has been linked to the development of the metabolic syndrome (MetS; Pasquali et al. 2006). The metabolic effects of GC are directed both toward the recruitment of energy stores for gluconeogenesis (peripheral effects) and toward the augmentation of energy stores by adjusting feeding behavior and intake of palatable foods to compensate for the energy loss (central effects). Increased GC exposure will increase food intake and insulin levels, facilitating the development of obesity and the MetS (Warne et al. 2009, Dallman 2010). In accordance, patients with Cushing's syndrome, which is caused by prolonged excessive exposure to GC, exhibit many features of the MetS (Newell-Price et al. 2006) associated with increased cardiovascular morbidity and mortality (Dekkers et al. 2007). Finally, manipulation of cortisol exposure at the tissue level in mice, through stimulation or abrogation of $11 \beta$-hydroxysteroid dehydrogenase type- 1 and -2 (11 $\beta$-HSD-1 and -2 ) activity can increase or regress visceral fat accumulation, as well as other features of the MetS (Masuzaki et al. 2001, Cooper \& Stewart 2009).

Nonetheless, it is still controversial how the development of the MetS and its complications affect the activity of the HPA axis. Common features of the MetS, like insulin resistance and obesity, are reproducibly induced in mouse models of diet-induced obesity (DIO) by feeding of high fat diet (HFD), but the effects on the activity of the HPA axis have been evaluated in only a minority of these studies, and their results are conflicting. Many factors, like differences in mouse strains, housing, and sampling conditions, but also the content and duration of the diets, affect the activity of the HPA axis and preclude simple comparisons after induction of DIO. In addition, the evaluation of the HPA axis in most studies was restricted to a single measurement of plasma 
corticosterone levels, which was combined with either $11 \beta-H S D-1$ enzyme activity in peripheral tissues or in the CNS in only a few of these studies (Auvinen et al. 2011).

Therefore, the aim of the present study was to evaluate the effects of HFD in mice in detail on basal, nonstressed activity of the HPA axis, using standardized evaluations that control for housing and sampling conditions. For these studies, we used C57Bl/6J mice that develop obesity and insulin resistance upon the HFD (Surwit et al. 1988, West et al. 1992, Parekh et al. 1998, Kleinridders et al. 2009).

\section{Materials and Methods}

\section{Mouse strain, housing, and diets}

In the current study we used male C57Bl/6J mice (Charles River, Maastricht, The Netherlands), which develop obesity and insulin resistance, specific features of the MetS (Surwit et al. 1988, West et al. 1992, Parekh et al. 1998, Kleinridders et al. 2009). Twelve-week-old mice $(n=36)$ were single housed in a separate room from other experimental animals in the facility to minimize environmental stressors and maintained on a $12 \mathrm{~h}$ light: $12 \mathrm{~h}$ darkness cycle (lights on $0700 \mathrm{~h}$ ) at controlled room temperature $\left(21-22^{\circ} \mathrm{C}\right)$ and fed ad libitum with free access to drinking water. Mice were weightmatched and randomly assigned to the following diets for 12 weeks: HFD (45 energy \% lard fat, D12451; Research Diet Services, Inc., New Brunswick, NJ, USA) $(n=18)$ or low fat diet (LFD) (10 energy \% lard fat, D12451B; Research Diet Services, Inc.) $(n=18)$. All mice were fed the LFD for 3 weeks before starting the HFD.

All animal experiments were performed in accordance with the regulations of Dutch law on animal welfare and the institutional ethics committee for animal procedures from the Leiden University Medical Center approved the protocol.

\section{Sampling of corticosterone}

Mice on the LFD $(n=18)$ and HFD $(n=18)$ were divided into two groups of nine mice, and blood for the measurement of plasma corticosterone levels was sampled at weeks 1,5 , and 9 (first group) or at weeks 3, 7, and 11 (second group). Blood samples were collected during the first light hour at $0700 \mathrm{~h}$, at $1200 \mathrm{~h}$, and during the last light hour at $1800 \mathrm{~h}$. To establish that the peak plasma corticosterone peak had not 'shifted' toward the dark hours of the light/dark cycle, at week 11, plasma corticosterone was measured at 1900, 2000, and $2100 \mathrm{~h}$ during the dark phase in red light conditions. All corticosterone samples were obtained within $90 \mathrm{~s}$ from disturbing the cage, via tail incision, allowing the mouse to move freely on top of the home cage (Dalm et al. 2005). Plasma insulin was measured after a 4-h fast in the same weeks as corticosterone. Plasma leptin levels were determined from the trunk blood after decapitation. After 12 weeks, the mice were decapitated within $90 \mathrm{~s}$ from disturbing the cage, either in the morning (0900-1000 h) or during the last light hour $(1800-1900 \mathrm{~h})$. After decapitation, the trunk blood was collected and the brain was harvested and snap-frozen in isopentane and stored at $-80^{\circ} \mathrm{C}$. Liver, muscle, gonadal, abdominal visceral, and subcutaneous fat pads were dissected, snap-frozen in liquid nitrogen, and stored at $-80^{\circ} \mathrm{C}$.

\section{Plasma hormone measurements}

Plasma corticosterone levels were determined by RIA (MP Biomedicals LLC, Orangeburg, NY, USA; intra-assay variation $7 \cdot 3 \%$ and inter-assay variation $6 \cdot 9 \%$ ).

Insulin and leptin were measured by ELISA (Crystal Chem, Inc., Downers Grove, IL, USA; intra-assay precision coefficient of variation $(\mathrm{CV}) \leq 10 \%$ and inter-assay precision $\mathrm{CV} \leq 10 \%$ for both kits). All measurements were assayed according to the manufacturer's instructions.

\section{Evaluation of HPA axis activity in the CNS (in situ hybridization)}

Brain sections of $16 \mu \mathrm{m}$ of the paraventricular nucleus (PVN; Bregma $-0.70 \mathrm{~mm}$ ), amygdale (Bregma $-0.70 \mathrm{~mm}$ ), and hippocampus (Bregma $-1.70 \mathrm{~mm}$ ) were cut according to the brain atlas of Paxinos \& Fraklin (2001) on a cryostat and mounted on polysine microscope slides (Menzel-Gläzer, Braunschweig, Germany) and stored at $-80^{\circ} \mathrm{C}$ until further use. The hybridization was performed as described previously (Meijer et al. 1997) with minor adjustments. Briefly, sections were fixed in $4 \%$ paraformaldehyde, further permeabilized by proteinase $\mathrm{K}$ treatment, acetylated twice with $0 \cdot 25 \%$ acetic anhydride in $0.1 \mathrm{M}$ triethanolamine, and dehydrated in a graded ethanol series.

Riboprobes were generated from linearized constructs containing the respective cDNAs in pBluescript. A $500 \mathrm{bp}$ SalI-HindIII fragment of exon 2 of the mouse gene was used for glucocorticoid receptor (GR; Veenema et al. 2003). The cRNA from corticotropin-releasing hormone $(\mathrm{CRH})$ was transcribed from a $1 \mathrm{~kb}$ cDNA insert in pGEM 4 containing the full-length coding region of rat $\mathrm{CRH}$ (Lachize et al. 2009). ${ }^{35}$ S-UTP-labeled antisense probes were generated using the appropriate polymerase using a standard protocol.

A hybridization mix was prepared containing $60 \%$ deionized formamide, $10 \%$ dextran $\mathrm{SO}_{4}, 2 \times \mathrm{SSC}$, $0 \cdot 1 \mathrm{mg} / \mathrm{ml}$ yeast tRNA, $0 \cdot 1 \mathrm{mg} / \mathrm{ml}$ sssDNA, $10 \mathrm{mM}$ dithiothreitol, and $0.05 \mathrm{M}$ PBS. All radiolabeled probes were diluted to $16.7 \times 10^{6}$ c.p.m. $/ \mathrm{ml}$. Of these mixtures, $120 \mu \mathrm{l}$ were applied to each slide and then covered with a coverslip. The sections were hybridized overnight in a moisturized chamber at $55^{\circ} \mathrm{C}$. The next day, the coverslips were removed carefully and sections were washed in $2 \times$ SSC for $10 \mathrm{~min}$ at room temperature. After washing, sections were treated with RNAse A $(2 \mathrm{mg} / 100 \mathrm{ml}$ in $0.5 \mathrm{~mol} / 1 \mathrm{NaCl}, 0.1 \mathrm{~mol} / 1$ Tris, $\mathrm{pH} 7.5)$ at $37^{\circ} \mathrm{C}$ for $10 \mathrm{~min}$ and subsequently washed at $55^{\circ} \mathrm{C}$ in $2 \times$ SSC for $10 \mathrm{~min}, 1 \times \mathrm{SSC}$ for $10 \mathrm{~min}, 0 \cdot 1 \times \mathrm{SSC}$ for $2 \times 30 \mathrm{~min}$, and, finally, at room temperature in $0 \cdot 1 \times$ SSC for $5 \mathrm{~min}$. 
Sections were dehydrated in an ethanol series (70, 80, 96 and $100 \%$ ethanol) and dried on air. Signal was visualized with exposure of Kodak Biomax MR films, scanned and quantified by using Image $\mathrm{J}$ software (National Institutes of Health) and related to standard curves of ${ }^{14} \mathrm{C}$ (RPA 504 microscales; Amersham). Two sections per mouse per brain area were quantified. For CRH mRNA in the PVN and amygdala and for GR mRNA in the PVN, the values represent a sum of the two areas measured. For GR mRNA in the hippocampus, the values represent the average of the two measurements.

\section{$11 \beta$-HSD-1 and -2 expression analyses in liver and adipose} tissues

Total RNA was extracted from liver and adipose tissues using the Nucleospin RNA II kit (Macherey-Nagel, Düren, Germany) according to the manufacturer's instructions. RNA quality was examined with lab-on-a-chip technology using Experion StdSens analysis kit (Bio-Rad). Total RNA was reverse-transcribed with iScript cDNA synthesis kit (Bio$\mathrm{Rad}$ ) and the obtained cDNA was purified with Nucleospin Extract II kit (Macherey-Nagel). Real-time PCR for 11ß-HSD-1 (forward primer: CAGCAAAGGGATTGGAAGAG; reverse primer: CTTTCCCGCCTTGACAATAA) and 11ß-HSD-2 (forward primer: TTTGGTGCACTTGAGCTGAC; reverse primer: AGCCGAATGTGTCCATAAGC) were carried out on the IQ5 PCR machine (Bio-Rad) using the Sensimix SYBR Green RT-PCR mix (Quantace Ltd, London, UK). mRNA levels were normalized to mRNA levels of cyclophilin (forward primer: CAAATGCTGGACCAAACACAA; reverse primer: GCCATCCAGCCATTCAGTCT) and hypoxanthine guanine phosphoribosyl transferase (forward primer: TTGCTCGAGATGTCATGAAGGA; reverse primer: AGCAGGTCAGCAAAGAACTTATAG).

\section{Statistical analysis}

Data are presented as means \pm s.D. Statistical differences were calculated using the Mann-Whitney $U$ test for nonparametric data, with GraphPad Prism, version 5.01 (GraphPad Software Inc., La Jolla, USA). $P<0.05$ was considered as statistically significant.

\section{Results}

HFD increases plasma insulin and leptin levels and body weight without affecting thymus weight

As anticipated, HFD feeding resulted in a greater increase in body weight than the LFD, which already reached significance within 1 week, and this difference remained significant throughout the experiment (Fig. 1A). The HFD did not affect the thymus weight (Fig. 1B). The HFD increased plasma insulin concentrations already within 1 week (Fig. 1C), which
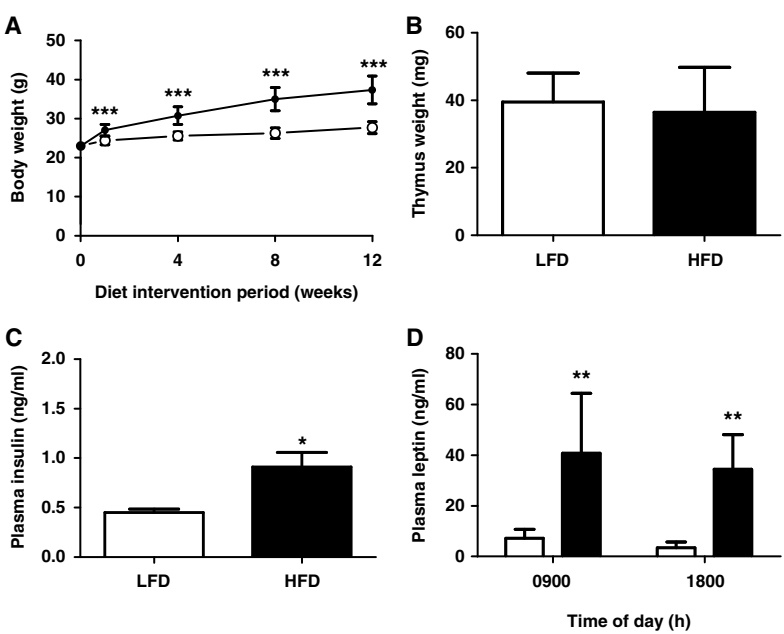

Figure 1 Effect of diet on male C57Bl/6) mice fed an LFD (open circles and bars) or HFD (closed circles and bars) on (A) body weight, (B) thymus weight at week 12, (C) plasma insulin concentrations at week 1 , and (D) plasma leptin levels at week 12, Mann-Whitney $U$ test, ${ }^{*} P<0 \cdot 01,{ }^{*} P<0 \cdot 001$, ${ }^{* * *} P<0 \cdot 0001$.

remained significantly increased throughout the experiment. Plasma leptin levels were significantly increased after 12 weeks of the HFD both at 0900 and $1800 \mathrm{~h}$ (Fig. 1D).

HFD decreases diurnal peak plasma corticosterone levels both acutely and in the long term

A diurnal corticosterone rhythm was observed in all animals, with a nadir in the morning $(0700 \mathrm{~h})$ and with peak values during the last light hour before the dark phase $(1800 \mathrm{~h})$. The HFD decreased plasma corticosterone levels within 1 week by $44 \%$ at $1200 \mathrm{~h}$ and by $52 \%$ at $1800 \mathrm{~h}$ in the evening (Fig. 2A). This decrease in evening peak corticosterone levels persisted throughout the experiment at week 7 and 12 (Fig. 2B and D). Furthermore, peak corticosterone levels were not 'shifted' toward the dark hours of the light/dark cycle but declined from the 1800 to $1900 \mathrm{~h}$ time-points in both LFD and HFD groups. The suppression of plasma corticosterone levels was also evident in the HFD group during the beginning of the dark phase (at 1900, $2000 \mathrm{~h}$ ) at week 11 when compared with the LFD group (Fig. 2C).

HFD induces changes in $m R N A$ expression of $C R H$ and $G R$ in the brain

The HFD significantly decreased CRH mRNA expression in the PVN and amygdala at $0900 \mathrm{~h}$ (Fig. 3A and B). Moreover, the HFD decreased GR mRNA in the PVN at $0900 \mathrm{~h}$ in the morning basal period (Fig. 3C). The HFD increased CRH mRNA expression at $1800 \mathrm{~h}$ in both PVN and amygdale (Fig. 3A and B). Furthermore, the HFD increased GR mRNA in the evening in the CA1 region (Fig. 3D), but not in the other regions (CA3 and dentate gyrus (DG) of the hippocampus) (Fig. 3E and F). 


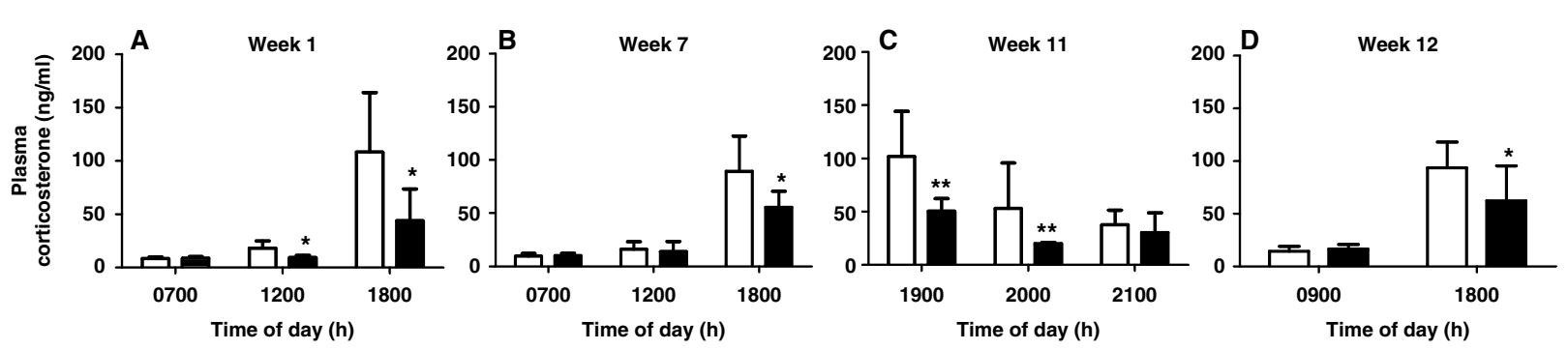

Figure 2 Effect of the HFD on circadian plasma corticosterone. Male C57Bl/6J mice were fed an LFD (open bars) or HFD (closed bars), and plasma corticosterone was determined in the morning $(0700 \mathrm{~h})$, at noon $(1200 \mathrm{~h})$, or at the evening peak (1800 h) (A) after $1 \mathrm{week}$ and (B) 7 weeks. (C) At 11 weeks corticosterone was determined at 1900, 2000, and $2100 \mathrm{~h}$ ( $n=6$ per time point) and (D) at 12 weeks at 0900 and 1800 h. Mann-Whitney $U$ test, $* P<0 \cdot 05$. ${ }^{* *} P<0 \cdot 01$.

HFD feeding induces opposite changes in $11 \beta-H S D-1 \mathrm{mRNA}$ expression in adipose tissue and liver, whereas $11 \beta-H S D-2$ $m R N A$ expression remains unaffected

The HFD decreased 11ß-HSD-1 expression in gonadal, visceral, and subcutaneous adipose tissues both in the morning by 65, 37, and 66\% respectively (Fig. 4B, C and D) and in the evening by 62,47 , and $67 \%$ respectively, whereas no changes were observed in $11 \beta-H S D-2$ expression in the same tissues at both time-points (Fig. 4B, C and D). By contrast, in the liver, the HFD increased 11 $\beta$-HSD-1 expression at $1800 \mathrm{~h}$ by $+23 \%$ whereas $11 \beta-\mathrm{HSD}-2$ expression was not affected (Fig. 4A).

\section{Discussion}

This study aimed to characterize in detail, using standardized evaluations that control for housing and sampling conditions, the diet-induced changes that occur in basal activity of the HPA axis in the C567Bl/6J mouse model that develops obesity and insulin resistance, distinct features of the MetS. HFD feeding resulted in downregulation of the activity of the HPA axis, as reflected in decreased diurnal corticosterone concentrations, decreased $11 \beta-H S D-1$ enzyme expression in peripheral tissues, and altered $\mathrm{CRH}$ and GR expression in the CNS (decreased in the morning and increased in the evening). These observations indicate that the HFD induces complex changes in the diurnal regulation of the different components of the HPA axis. These changes are not unequivocally characterized by increased, but rather by decreased, HPA axis activity.

As expected, the HFD significantly increased both body weight and plasma insulin concentrations already within 1 week and reduced diurnal corticosterone levels already within 1 week that persisted throughout the experiment. This persistent reduction in circulating corticosterone levels was not due to a shift in the diurnal peak of corticosterone and was evident from 1800 to $2000 \mathrm{~h}$.

Several mechanisms may explain the early decrease in diurnal corticosterone peak levels upon the HFD. First, hypercortisolism in human obesity has not been established and cortisol secretion is increased in obese humans, primarily because of increased clearance and increased distribution volume of the circulating cortisol resulting in secondary central activation of the HPA axis (Roelfsema et al. 2009, 2010). Second, this decrease in diurnal corticosterone peak levels may reflect counteracting mechanisms directed toward prevention of further progression in insulin resistance, both centrally and in peripheral tissues. Third, circulating leptin concentrations increase proportionally to the fat mass gained (Van Heek et al. 1997) and leptin and insulin resistance have been documented to develop already within 3 days of high fat feeding (Wang et al. 2001).

In accordance, the HFD resulted in increased CRH mRNA expression in the PVN and an increase in GR mRNA expression in the CA1 region of the hippocampus in the evening, representing reduced negative feedback by decreased circulating corticosterone levels. This increase in GR mRNA in the CA1 region of the hippocampus also indicates that CNS areas important for specific types of learning and memory are relatively preserved in the presence of the HFD and subsequent dampening of the HPA axis. In accordance, reduction of GC levels in a specific mouse model of insulin resistance $(d b / d b)$ reverses the cognitive impairment related to hippocampal neurons induced by insulin resistance (Stranahan et al. 2008). These findings imply that dampening of the HPA axis in the presence of insulin resistance, induced by the HFD, might be a mechanism to rescue hippocampal neurons from impairments and to maintain normal cognitive function. In addition, both leptin and insulin can activate proopiomelanocortin (POMC) neurons (Williams et al. 2010) that produce ACTH. However, glucose sensing by POMC neurons is impaired in obese mice (Parton et al. 2007), which may result in insufficient adrenal stimulation by ACTH (diminished forward coupling between ACTH and corticosterone) resulting in decreased diurnal peak corticosterone and reduced negative feedback. In addition, the potency of ACTH is decreased in obesity (Roelfsema et al. 2009).

Intriguingly, there is a disparity between the effects of the HFD on the activity of the HPA axis in the morning as compared with the evening. Whereas the central activation in the evening can be easily explained by reduced negative feedback as a result of reduced peak corticosterone levels, the 

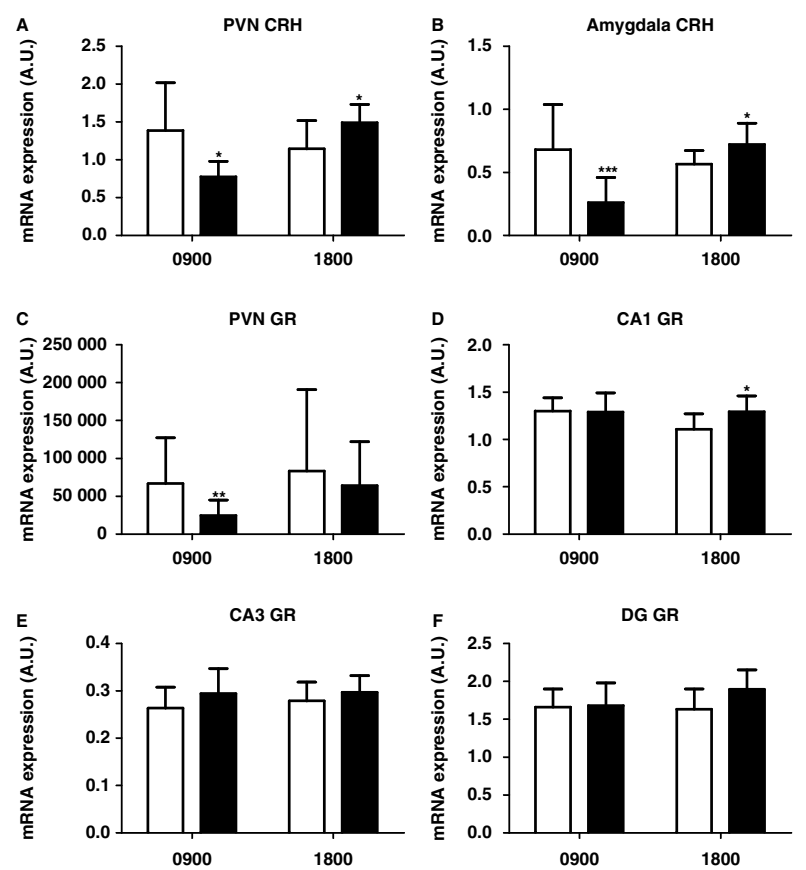

Figure 3 Effect of the HFD on mRNA expression of CRH and GR in the hypothalamus and hippocampus. Male $\mathrm{C} 57 \mathrm{Bl} / 6 \mathrm{~J}$ mice were fed an LFD (open bars) or HFD (closed bars) for 12 weeks, and mRNA expression was determined: $\mathrm{CRH}$ in the (A) PVN and (B) amygdale, and GR in the (C) PVN, (D) CA1, (E) CA3, and (F) DG regions of the hippocampus in the morning $(0900 \mathrm{~h})$ and evening $(1800 \mathrm{~h})$ (black bars). Mann-Whitney $U$ test, ${ }^{*} P \leq 0 \cdot 05, * * P<0 \cdot 01, * * * P<0 \cdot 001$.

central inhibition of CRH and GR expression found in the morning in the presence of unaltered circulating corticosterone levels is very difficult to explain. To the best of our knowledge, such a disparity has not been previously documented or investigated. This further exemplifies that the HFD induces complex changes in the diurnal regulation of the different components of the HPA axis. It is also likely that other factors outside the individual components of the HPA axis influence these complex effects of dietary intervention. Reduction of hypothalamic $\mathrm{CRH}$ expression in the morning might include the following mechanisms. For instance, induction of leptin resistance in the presence of obesity induces an increase in endocannabinoid tone (Scherer \& Buettner 2009, Bermudez-Silva et al. 2012), which could lead to the suppression of CRH. However, leptin resistance induced by high fat feeding is selective and does not impact on autonomic nervous system activity (Enriori et al. 2011). Thus, it could be speculated that hyperleptinemia dampens $\mathrm{CRH}$ expression and release in the face of selective sensitivity of the central HPA axis. It has also been shown in in vitro studies that leptin can reduce the sensitivity of adrenal cortex cells to ACTH, thereby reducing circulating corticosterone levels (Kruse et al. 1998, Hsu et al. 2006). However, the present data do not permit firm conclusions in this respect. In addition, a true effect of the diet per se cannot be excluded as no differences were observed in plasma corticosterone levels in the morning, although it is well possible that small changes in circulating corticosterone levels at the moment of the diurnal nadir are not detected. The observed decreased expression of hypothalamic GR expression, however, is not explained because it suggests increased corticosterone exposure.

Downregulation of CRH mRNA in the morning was accompanied by the downregulation of CRH mRNA and in the amygdala. Activation of the amygdala promotes HPA axis activation and previous studies in rats have shown an increase in circulating GC (Schulkin et al. 1994), whereas adrenalectomy decreases (Santibañez et al. 2005) $\mathrm{CRH}$ in the amygdala. Furthermore, increased $\mathrm{CRH}$ in the amygdala mediates anxiety-like behavior during stress (Makino et al. 1994) and the HFD decreases anxiety-like behaviors facilitating stress recovery (Buwalda et al. 2001, Pecoraro et al. 2004). Thus, HFD-induced reduction of $\mathrm{CRH}$ expression in the amygdala enables protection from further exposure to systemic GC.

In accordance, the effects of the HFD on the peripheral activity of the HPA axis were characterized by reduced mRNA expression of $11 \beta-H S D-1$ in adipose tissues. It has been proposed that this may reflect a mechanism to counteract tissue-specific insulin resistance (Man et al. 2011). These differential, fat depot-specific effects are in agreement with a recently proposed, dynamic, and depotselective relationship between adipose tissue $11 \beta-H S D-1$ activity and fat mass (Man et al. 2011). The HFD increases lipoprotein lipase activity (Petit et al. 2007), which would direct circulating triglycerides toward peripheral adipose tissues for storage. Corticosterone impairs glucose tolerance (Karatsoreos et al. 2010) and is a lipolytic hormone (Campbell et al. 2011). Therefore downregulation of $11 \beta-H S D-1$
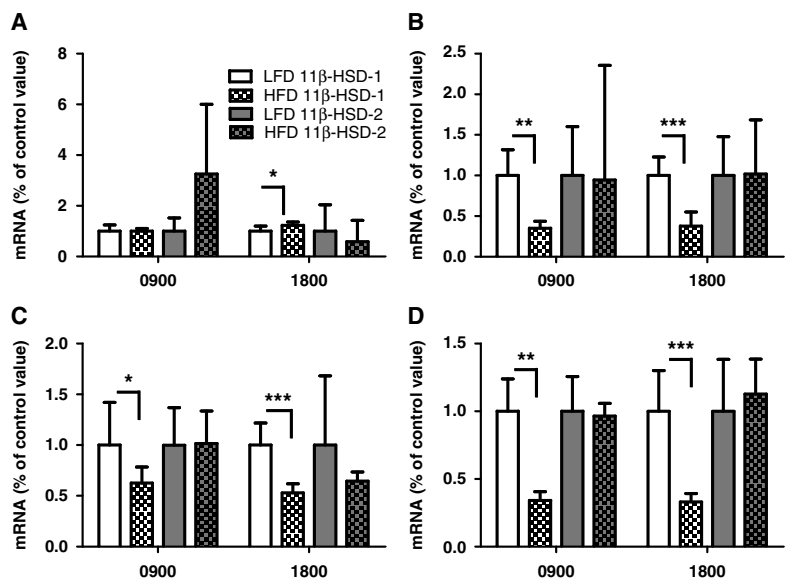

Figure 4 Effect of HFD on 11 $\beta$-HSD-1 and -2 expression in peripheral tissues. Male C57Bl/6J mice were fed an LFD (open bars) or HFD (chequered bars) for 12 weeks, and $11 \beta$-HSD-1 (white bars) and $11 \beta-H S D-2$ (gray bars) mRNA expression was determined in (A) the liver and (B) gonadal, (C) visceral, and (D) subcutaneous adipose tissues in the morning and evening. Mann-Whitney $U$ test, $* P<0 \cdot 05, * * P<0 \cdot 01, * * * P<0 \cdot 001$. 
expression would protect the adipose tissue from further insulin resistance. These observations are further strengthened by the fact that $11 \beta$-HSD-2 expression in the same tissues was not affected, resulting in overall reduction of GC exposure of the tissues.

In conclusion, we found that the HFD has profound effects on the basal, thus nonstressed, activity of the HPA axis, reflected in reduced diurnal corticosterone concentrations, distinct expression of CRH in the CNS across the diurnal rhythm, and reduced 11 $\beta$-HSD-1 enzyme expression in peripheral fat tissues. The observed effects in this study, both in the CNS and peripheral adipose tissues (downregulation of CRH mRNA and 11 $\beta$-HSD-1 enzyme mRNA respectively), are in agreement with the well-known metabolic effects of GC that are directed toward recruitment and augmentation of energy stores. In the presence of HFDinduced obesity or palatable foods, the HPA axis adapts.

\section{Declaration of interest}

The authors declare that there is no conflict of interest that could be perceived as prejudicing the impartiality of the research reported.

\section{Funding}

This research did not receive any specific grant from any funding agency in the public, commercial, or not-for-profit sector.

\section{Author contribution statement}

$\mathrm{H}$ E A researched data, contributed to the discussion, and wrote the manuscript. J A R, N R B, H P, L M H, J W A S, and P C N R contributed to the discussion and reviewed the edited manuscript. A M P contributed to the discussion and wrote the manuscript.

\section{Acknowledgements}

Patrick C N Rensen is an established investigator of the Netherlands Heart Foundation (grant number NHS2009T038).

\section{References}

Auvinen HE, Romijn JA, Biermasz NR, Havekes LM, Smit JWA, Rensen PCN \& Pereira AM 2011 Effects of high fat diet on basal activity of the hypothalamus-pituitary-adrenal axis in mice: a systematic review. Hormone and Metabolic Research 43 899-906. (doi:10.1055/s-0031-1291305)

Bermudez-Silva FJ, Cardinal P \& Cota D 2012 The role of the endocannabinoid system in the neuroendocrine regulation of energy balance. Journal of Psychopharmacology 26 114-124. (doi:10.1177/ 0269881111408458)

Buwalda B, Blom WA, Koolhaas JM \& van Dijk G 2001 Behavioral and physiological responses to stress are affected by high-fat feeding in male rats. Physiology \& Behavior 73 371-377. (doi:10.1016/S0031-9384(01)00493-0)

Campbell JE, Peckett AJ, D'souza AM, Hawke TJ \& Riddel MC 2011 Adipogenic and lipolytic effects of chronic glucocorticoid exposure. American Journal of Physiology. Cell Physiology 300 C198-C209. (doi:10.1152/ajpcell.00045.2010)
Cooper MS \& Stewart PM 2009 11ß-Hydroxysteroid dehydrogenase type 1 and its role in the hypothalamus-pituitary-adrenal axis, metabolic syndrome, and inflammation. Journal of Clinical Endocrinology and Metabolism 94 4645-4654. (doi:10.1210/jc.2009-1412)

Dallman MF 2010 Stress-induced obesity and the emotional nervous system. Trends in Endocrinology and Metabolism 21 159-165. (doi:10.1016/j.tem. 2009.10.004)

Dalm S, Enthoven L, Meijer OC, van der Mark MH, Karssen AM, de Kloet ER \& Oitzl MS 2005 Age-related changes in hypothalamic-pituitary-adrenal axis activity of male C57BL/6J mice. Neuroendocrinology 8 372-380. (doi:10. 1159/000089555)

Dekkers OM, Biermasz NR, Pereira AM, Roelfsema F, van Aken MO, Voormolen JH \& Romijn JA 2007 Mortality in patients treated for Cushing's disease is increased, compared with patients treated for nonfunctioning pituitary macroadenoma. Journal of Clinical Endocrinology and Metabolism 92 976-981. (doi:10.1210/jc.2006-2112)

Enriori PJ, Sinnayah P, Simonds SE, Garcia Rudaz C \& Cowley MA 2011 Leptin action in the dorsomedial hypothalamus increases sympathetic tone to brown adipose tissue in spite of systemic leptin resistance. Journal of Neuroscience 31 12189-12197. (doi:10.1523/JNEUROSCI.2336-11.2011)

Hsu HT, Chang YC, Chiu YN, Liu CL, Chang KJ \& Guo IC 2006 Leptin interferes with adrenocorticotropin $/ 3^{\prime}, 5^{\prime}$-cyclic adenosine monophosphate (cAMP) signaling, possibly through a Janus kinase 2-phosphatidylinositol 3-kinase/Akt-phosphodiesterase 3-cAMP pathway, to down-regulate cholesterol side-chain cleavage cytochrome P450 enzyme in human adrenocortical NCI-H295 cell line. Journal of Clinical Endocrinology and Metabolism 91 2761-2769. (doi:10.1210/jc.2005-2383)

Karatsoreos IN, Bhagat SM, Bowles MP, Weil ZM, Pfaff DW \& McEwen BS 2010 Endocrine and physiological changes in response to chronic corticosterone: a potential model of metabolic syndrome in mouse. Endocrinology 151 2117-2127. (doi:10.1210/en.2009-1436)

Kleinridders A, Schenten D, Konner AC, Belgardt BF, Mauer J, Okamura T, Wunderlich FT, Medzhitov R \& Bruning JC 2009 MyD88 signaling in the CNS is required for development of fatty acid-induced leptin resistance and diet-induced obesity. Cell Metabolism 10 249-259. (doi:10.1016/j.cmet. 2009.08.013)

Kruse M, Bornstein SR, Uhlmann K, Paeth G \& Scherbaum WA 1998 Leptin down-regulates the steroid producing system in the adrenal. Endocrine Research 24 587-590. (doi:10.3109/07435809809032650)

Lachize S, Apostolakis EM, van der Laan S, Tijssen AM, Xu J, de Kloet ER \& Meijer OC 2009 Steroid receptor coactivator-1 is necessary for regulation of corticotropin-releasing hormone by chronic stress and glucocorticoids. PNAS 106 8038-8042. (doi:10.1073/pnas.0812062106)

Makino S, Gold PW \& Schulkin J 1994 Effects of corticosterone on CRH mRNA and content in the bed nucleus of the stria terminalis; comparison with the effects in the central nucleus of the amygdala and the paraventricular nucleus of the hypothalamus. Brain Research 657 141-149. (doi:10.1016/0006-8993(94)90961-X)

Man TY, Michailidou Z, Gokcel A, Ramage L, Chapman KE, Kenyon CJ, Seckl JR \& Morton NM 2011 Dietary manipulation reveals an unexpected inverse relationship between fat mass and adipose $11 \beta$-hydroxysteroid dehydrogenase type 1. American Journal of Physiology. Endocrinology and Metabolism 300 E1076-E1084. (doi:10.1152/ajpendo.00531.2010)

Masuzaki H, Paterson J, Shinyama H, Morton NM, Mullins JJ, Seckl JR \& Flier JS 2001 A transgenic model of visceral obesity and the metabolic syndrome. Science 294 2166-2170. (doi:10.1126/science.1066285)

Meijer OC, Cole TJ, Schmid W, Schütz G, Joëls M \& De Kloet ER 1997 Regulation of hippocampal 5-HT1A receptor mRNA and binding in transgenic mice with a targeted disruption of the glucocorticoid receptor. Brain Research. Molecular Brain Research 46 290-296. (doi:10.1016/S0169328X(97)00002-8)

Newell-Price J, Bertagna X, Grossman AB \& Nieman LK 2006 Cushing's syndrome. Lancet 367 1605-1617. (doi:10.1016/S0140-6736(06)68699-6)

Parekh PI, Petro AE, Tiller JM, Feinglos MN \& Surwit RS 1998 Reversal of diet-induced obesity and diabetes in C57BL/6J mice. Metabolism 47 1089-1096. (doi:10.1016/S0026-0495(98)90283-9) 
Parton LE, Ye CP, Coppari R, Enriori PJ, Choi B, Zhang CY, Xu C, Vianna CR, Balthasar N, Lee CE et al. 2007 Glucose sensing by POMC neurons regulates glucose homeostasis and is impaired in obesity. Nature 449 228-232. (doi:10.1038/nature06098)

Pasquali R, Vicennati V, Cacciari M \& Pagotto U 2006 The hypothalamicpituitary-adrenal axis in obesity and the metabolic syndrome. Annals of the New York Academy of Sciences 1083 111-128. (doi:10.1196/annals.1367.009)

Paxinos G \& Fraklin KGB 2001 The Mouse Brain in Stereotaxic Coordinates. San Diego, CA: Academic Press.

Pecoraro N, Reyes F, Gomez F, Bhargava A \& Dallman MF 2004 Chronic stress promotes palatable feeding, which reduces signs of stress: feedforward and feedback effects of chronic stress. Endocrinology 145 3754-3762. (doi:10.1210/en.2004-0305)

Petit V, Arnould L, Martin P, Monnot MC, Pineau T, Besnard P \& Niot I 2007 Chronic high-fat diet affects intestinal fat absorption and postprandial triglyceride levels in the mouse. Journal of Lipid Research 48 278-287. (doi:10.1194/jlr.M600283-JLR200)

Roelfsema F, Kok P, Frolich M, Pereira AM \& Pijl H 2009 Disordered and increased adrenocorticotropin secretion with diminished adrenocorticotropin potency in obese in premenopausal women. Journal of Clinical Endocrinology and Metabolism 94 2991-2997. (doi:10.1210/jc.2009-0350)

Roelfsema F, Kok P, Pereira AM \& Pijl H 2010 Cortisol production rate is similarly elevated in obese women with or without the polycystic ovary syndrome. Journal of Clinical Endocrinology and Metabolism 95 3318-3324. (doi:10.1210/jc.2009-2701)

Santibañez M, Gysling K \& Forray MI 2005 Adrenalectomy decreases corticotropin-releasing hormone gene expression and increases noradrenaline and dopamine extracellular levels in the rat lateral bed nucleus of the stria terminalis. Journal of Neuroscience Research 81 140-152. (doi:10.1002/jnr.20538)

Scherer T \& Buettner C 2009 The dysregulation of the endocannabinoid system in diabesity - a tricky problem. Journal of Molecular Medicine $\mathbf{8 7}$ 663-668. (doi:10.1007/s00109-009-0459-y)

Schulkin J, McEwen BS \& Gold PW 1994 Allostasis, amygdala, and anticipatory angst. Neuroscience and Biobehavioral Reviews 18 385-396. (doi:10.1016/0149-7634(94)90051-5)
Stranahan AM, Arumugam TV, Cutler RG, Lee K, Egan JM \& Mattson MP 2008 Diabetes impairs hippocampal function through glucocorticoidmediated effects on new and mature neurons. Nature Neuroscience 11 309-317. (doi:10.1038/nn2055)

Surwit RS, Kuhn CM, Cochrane C, McCubbin JA \& Feinglos MN 1988 Diet-induced type II diabetes in C57BL/6J mice. Diabetes 37 1163-1167. (doi:10.2337/diabetes.37.9.1163)

Van Heek M, Compton DS, France CF, Tedesco RP, Fawzi AB, Graziano MP, Sybertz EJ, Strader CD \& Davis HR Jr 1997 Diet-induced obese mice develop peripheral, but not central, resistance to leptin. Journal of Clinical Investigation 99 385-390. (doi:10.1172/JCI119171)

Veenema AH, Meijer OC, de Kloet ER \& Koolhaas JM 2003 Genetic selection for coping style predicts stressor susceptibility. Journal of Neuroendocrinology 15 256-267. (doi:10.1046/j.1365-2826.2003.00986.x)

Wang J, Obici S, Morgan K, Barzilai N, Feng Z \& Rossetti L 2001 Overfeeding rapidly induces leptin and insulin resistance. Diabetes $\mathbf{5 0}$ 2786-2791. (doi:10.2337/diabetes.50.12.2786)

Warne JP, Akana SF, Ginsberg AB, Horneman HF, Pecoraro NC \& Dallman MF 2009 Disengaging insulin from corticosterone: roles of each on energy intake and disposition. American Journal of Physiology. Regulatory, Integrative, and Comparative Physiology 296 1366-1375. (doi:10.1152/ ajpregu.91016.2008)

West DB, Boozer CN, Moody DL \& Atkinson RL 1992 Dietary obesity in nine inbred mouse strains. American Journal of Physiology 262 1025-1032.

Williams KW, Margatho LO, Lee CE, Choi M, Lee S, Scott MM, Elias CF \& Elmquist JK 2010 Segregation of acute leptin and insulin effects in distinct populations of arcuate proopiomelanocortin neurons. Journal of Neuroscience 30 2472-2479. (doi:10.1523/JNEUROSCI.3118-09.2010)

Received in final form 16 May 2012

Accepted 22 May 2012

Made available online as an Accepted Preprint 22 May 2012 